\title{
A Self-Oscillating Boosting Amplifier with Adaptive Soft switching Control for Piezoelectric Transducers
}

\author{
Saifullah Amir, Student Member, IEEE, Ronan v. d. Zee, Member, IEEE, and Bram Nauta, Fellow, IEEE \\ University of Twente, IC Design group, Enschede, The Netherlands
}

\begin{abstract}
This paper describes the design of a high-voltage amplifier for a piezoelectric transducer used in underwater communication applications, which incorporates boosting and signal generation within a single boost converter stage improving the total efficiency of the system. The proposed architecture combines hysteretic ripple current-mode control with an adaptive soft switching technique to achieve improved power efficiency over the full output power range. This is achieved by dynamically controlling the inductor current ripple to keep the converter running in soft switching. The feedback control and the soft switching regulation are implemented in a $0.25 \mu \mathrm{m} 60 \mathrm{~V}$ TSMC process with an external power stage. The system achieves a peak efficiency of $85 \%$ at $20 \mathrm{~W}$ of output power up to $30 \mathrm{kHz}$ signal frequency.
\end{abstract}

Index Terms-Boost converter, continuous-conduction mode, hysteretic current-mode control, piezo driver, soft switching, power efficiency, minimum power-loss tracking.

\section{INTRODUCTION}

$\mathbf{U}$ NDERWATER Sensor Networks (USN's) have countless detection applications, such as pollution monitoring, seismic activity detection, environmental and harbour monitoring and many more. However, the development of reliable low power, low cost and high data rate sensor nodes is a major challenge in the practical implementation of such applications [1]. A typical USN consists of several network nodes spread across an area of interest, where each network node is capable of receiving and transmitting data to the neighbouring network node as shown in Fig. 1. Apart from problems like multi-path effects, localization and propagation delays, limited battery power is also one of the major issues in such systems. Therefore, USN nodes must be energy efficient as battery power is limited and recharging/replacing batteries is usually not practical.

Unlike electromagnetic and optical waves, acoustic waves have relatively low absorption in water and can be generated by using underwater piezoelectric transducers. However, for effective actuation of such transducers, high driving voltages are required (in the order of 10's to 100's of volts). With these battery-powered nodes having limited supply voltage, the requirement of the high voltage for piezoelectric transducers necessitates the use of supply boosting techniques.

As compared to some other architectures (like resonant amplifiers), the major requirement for the target application is to achieve a wide bandwidth of $0-30 \mathrm{kHz}$ and high signal swing at the output [2]. Linear amplifiers including class A, B and class $\mathrm{AB}$ can be used to generate the ac signal for actuation of the piezoelectric transducer. However, the inherently low

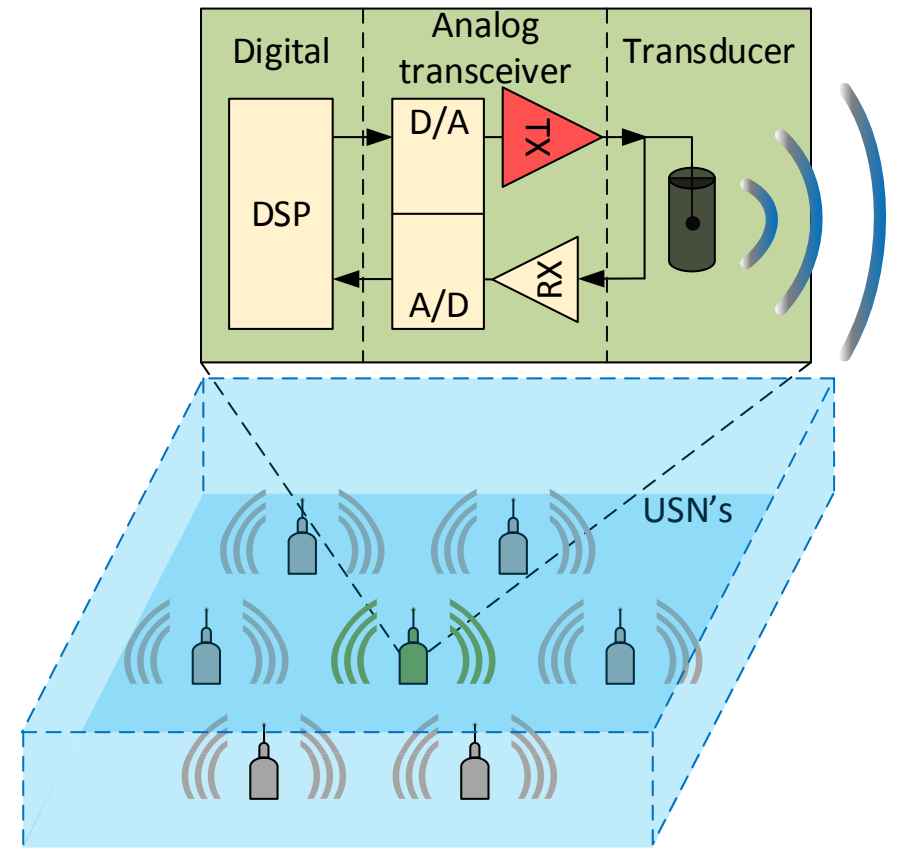

Fig. 1. A typical illustration of USN's with a single sensor

efficiency of these topologies make them unsuitable for battery powered applications.

Over the years, class-D amplifiers (a buck-type converter) have slowly taken over the area of sound generation because of their high efficiency [3], [4]. Despite these advantages, the class-D topology has its own limitations. The maximum signal swing in a class-D amplifier is limited to the supply voltage and hence cannot effectively drive the piezoelectric transducer with the limited battery voltage. This task is usually achieved by a two-stage solution, normally with a class-D amplifier for generation of dynamic signal and a dc-dc boost converter to increase the supply voltage of the class-D stage. Hence the total efficiency of the complete amplifier is lowered by the boost converter efficiency. Therefore, if the signal generation and the boosting could be performed in a single stage, the overall efficiency could be improved with a lower number of components, achieving a low cost solution.

Despite the efficiency advantage, boost converters have not gained significant popularity in direct signal generation in audio applications. This is because of the highly nonlinear control-to-output transfer characteristic and the risk of instability due to the presence of a Right-Half Plane Zero (RHPZ) for resistive loads, which results in limited bandwidth 
and high distortion at the output.

In applications involving underwater communication the maximum distortion requirement of the amplifier depends on the application and the used modulation scheme. Often, the spectral efficiency of modulation schemes for underwater communication is limited because of high noise from ships and waves, as well as time varying channel characteristics that include frequency dependent attenuation, dispersion, Doppler effects and severe multi-path caused by the seabed and temperature gradients. Compared to audio applications the resulting linearity requirements are less critical. In addition, the presence of the RHPZ at much higher frequencies in capacitive loads such as piezo-electric transducers used for acoustic communication [5], makes the use of a boost converter as a single stage solution an interesting option.

Piezoelectric actuators are available in a wide variety of frequencies and sizes. They are primarily capacitive, with a resistive component that is only present at frequencies where there is good coupling with the water and power transfer occurs. In this paper, we use a general model of the transducer impedance consisting of a parallel $\mathrm{RC}$ combination and a decoupling capacitor to block the DC path. The exact values are not specific for a particular transducer, but the operation and performance of the circuit are not dependent on the exact values either.

Several techniques have been developed in literature to use non-linear converters for direct dc-ac conversion and audio reproduction [6]-[15]. In [6]-[8], a boosting amplifier is proposed, that uses two complementarily boost converters with the load connected differentially. Although the cancellation of the second harmonic improves distortion, THD still remains relatively high.

The concept of pre-distortion, which works by compensating the non-linear parts of the transfer function in such a way that the complete signal transfer becomes linear, has also been reported in literature [10]-[13]. As the effectiveness of predistortion is dependent on the cancellation of the non-linear parts of the control-to-output transfer function, dynamic cancellation becomes challenging and often may require periodic calibration leading to more complexity. A recent approach described in [16], uses a bi-directional boost converter in combination with full-bridge to achieve high output voltage swing for a piezo actuator. The system is designed for very low bandwidth and output power, however.

The other technique for reducing distortion is by using feedback. The choice of feedback scheme determines the transient behaviour of the converter. Compared to traditional Voltage-Mode Control (VMC), hysteretic voltage mode control is popular in buck based converters due to its fast transient response and simplicity [17]. However, this technique cannot be directly applied in boost converters due to the inherent phase difference between the output voltage and inductor current [18]. In comparison to VMC, Peak Current-Mode Control (PCMC) as shown in Fig. 2, uses an additional current feedback loop. This makes the system dominantly first order and thus results in simpler compensation, more bandwidth and cycle by cycle current monitoring [19]. However, one of the major problem with peak or valley CMC is the unstable sub- harmonic oscillations occurring when the duty ratio $\mathrm{D}>0.5$. In order to reduce this effect, a fixed artificial slope $M_{a}$ can be subtracted from the control signal. Fixed slope compensation makes the system stable within a limited range of duty cycles, as less slope compensation can lead to instability and excessive slope compensation reduces the loop gain and makes the system approach VMC operation. Hence, to achieve good performance over wide duty cycle operation, complex adaptive slope compensation techniques depending on circuit components are required [20], [21]. In addition to linearity,

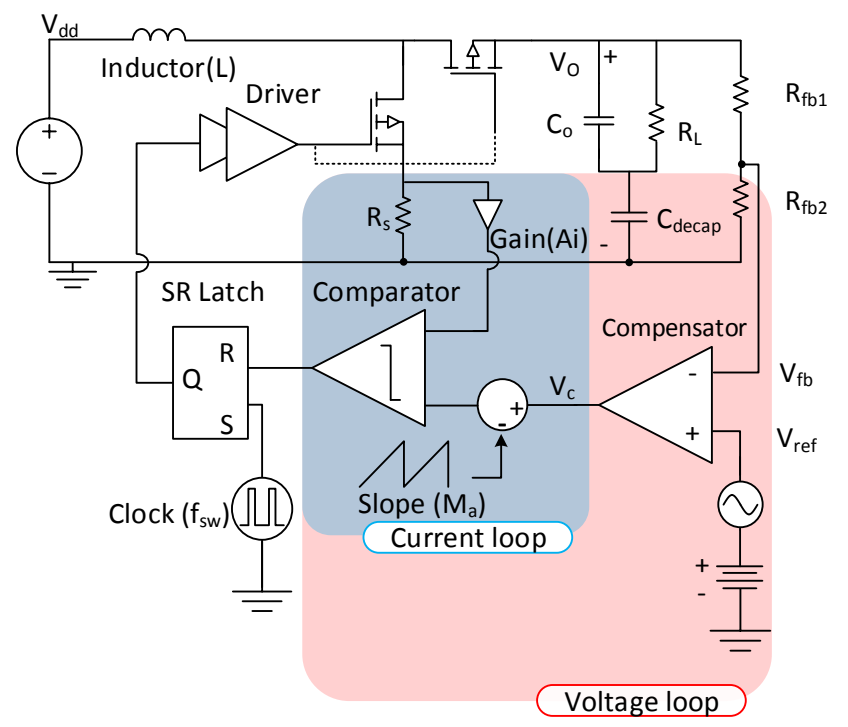

Fig. 2. Peak current mode control scheme

power efficiency is of crucial importance for developing low cost and low power USN's. In high voltage applications, soft switching can considerably reduce dissipation [22]-[24]. Traditional PCMC does not provide an easy way to keep the converter running in soft switching.

Therefore in this paper, the key idea is to use a boost converter for direct signal generation in a power efficient way. This is achieved by integrating Hysteretic Current-Mode Control (HCMC) (that achieves wide bandwidth and much greater stability) with fast cycle-by-cycle soft switching operation. Section 2 discusses in detail the proposed control scheme that improves the efficiency and bandwidth. In section 3, the system and circuit realizations are discussed. The proposed strategy is verified by measurement results in Section 4, and finally the conclusion is described in Section 5.

\section{RIPPLE HCMC AND SOFT SWITCHING REGULATION SCHEME}

In this section, ripple HCMC and the associated soft switching regulation scheme are proposed. The implementation and advantage of ripple HCMC is described and compared to traditional PCMC in subsection A. The mechanism of achieving minimum dissipation is discussed in subsection $\mathrm{B}$ and the adaptive soft switching regulation scheme that improves the efficiency is explained in subsection $\mathrm{C}$. 


\section{A. Ripple HCMC}

Traditional current mode control schemes have gained more popularity in recent years due to the advantages stated earlier. However, most of the fixed frequency solutions suffer from sub-harmonic stability issues resulting in limited loop gain and bandwidth. The HCMC technique as explained in [25], provides fast transient response, higher loop gain and better stability than traditional current mode control schemes, as will be shown later. Fig. 3 shows a simple implementation of a ripple HCMC based self-oscillating boost converter. In ripple HCMC, a fixed voltage $1 / 2 \Delta V_{\text {win }}$ is added and subtracted to the control signal $V_{c}$ to generate the hysteretic window in which the inductor current oscillates. The sensed inductor current is fed into the controller and the peak and valley crossing points are dependent on the hysteretic window to generate the pulse width modulated (PWM) signal. Compared to a hysteretic comparator implementation as described in [26], a separate error amplifier based structure is chosen here because it helps to control the average current that results in better frequency and voltage regulation [27]. In addition the noise immunity of the proposed structure with error amplifier is far superior to that of a comparator based scheme.

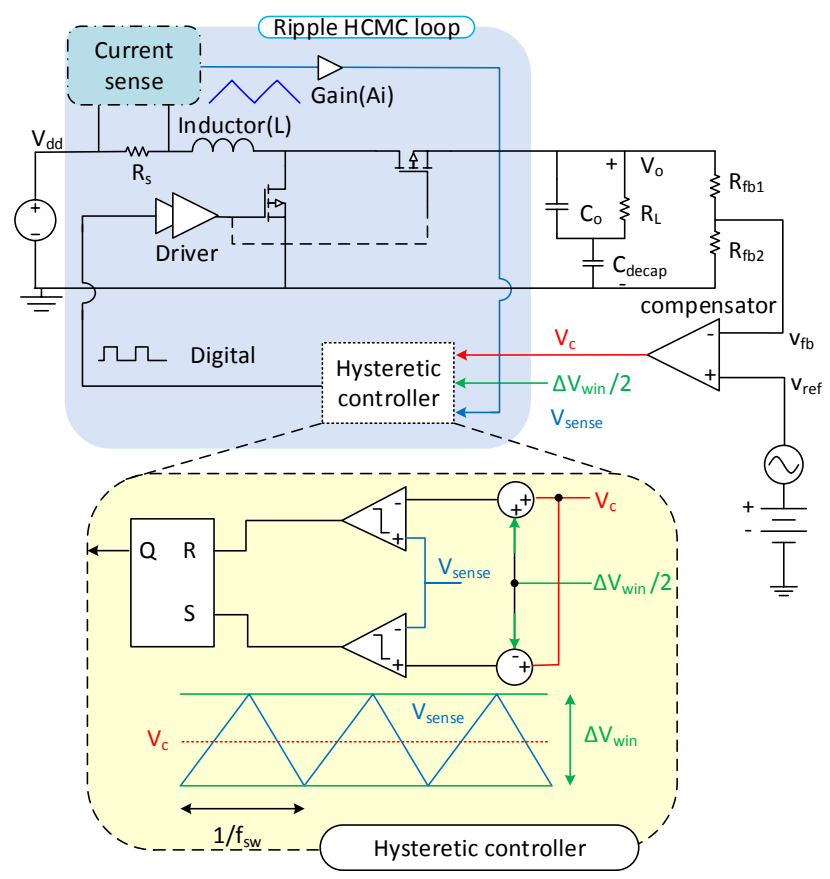

Fig. 3. Ripple HCMC scheme

Contrary to peak or valley $\mathrm{CMC}$, the switching frequency $f_{s w}$ is not fixed and is given by:

$$
f_{s w}=\frac{m_{1} * D}{\Delta V_{w i n}} * R_{s},\{D=0 . .1\}
$$

Where $R_{s}$ is the sense resistance, $m_{1}$ is the rising inductor current slope, $\mathrm{D}$ is the duty ratio and $V_{d d}$ is the supply voltage.

The variable switching frequency is a drawback of HCMC as it depends on several factors including input voltage, output voltage and hysteretic window. This creates some uncertainty with respect to electromagnetic interference (EMI), though the frequency band can roughly be controlled.

To determine the loop stability, the PCMC circuit in Fig. 2 and the HCMC circuit in Fig. 3 are modelled in SIMPLIS. In this way the inherent loop gain of both control schemes can be compared and validated. The circuit parameters are summarized in Table I. The values are chosen such that the systems display identical loop gain at higher frequencies.

The voltage loop gain and phase of both PCMC and HCMC

TABLE I

CIRCUIT PARAMETERS

\begin{tabular}{cc}
\hline \hline Parameters & Values \\
\hline Duty ratio (D) & 0.5 \\
Inductor (L) & $2 \mu \mathrm{H}$ \\
Current sense gain for PCMC $\left(\mathrm{R}_{\mathrm{s}} \cdot \mathrm{A}_{\mathrm{i}}\right)$ & $25 \mathrm{~m} \Omega * 15$ \\
Current sense gain for HCMC $\left(\mathrm{R}_{\mathrm{s}} \cdot \mathrm{A}_{\mathrm{i}}\right)$ & $25 \mathrm{~m} \Omega * 1$ \\
Supply voltage $\left(\mathrm{V}_{\mathrm{dd}}\right)$ & $9 \mathrm{~V}$ \\
Switching frequency $\left(\mathrm{f}_{\mathrm{sw}}\right)$ & $1 \mathrm{MHz}$ \\
Slope compensation (peak-peak)(PCMC) & $150 \mathrm{mV}$ \\
Compensator gain (PCMC) & 12 \\
Compensator gain (HCMC) & 1 \\
Output capacitance $\left(\mathrm{C}_{\mathrm{o}}\right)$ & $0.47 \mu \mathrm{F}$ \\
Resistance $\left(\mathrm{R}_{\mathrm{L}}\right)$ & $1 \mathrm{k} \Omega$ \\
Decoupling capacitance $\left(\mathrm{C}_{\text {decap }}\right)$ & $50 \mu \mathrm{F}$ \\
\hline
\end{tabular}

are compared in Fig. 4 and Fig. 5 respectively. HCMC provides more loop gain, even having a compensator gain of one. In PCMC the dc gain is reduced by the amount of slope compensation, while HCMC has no slope compensation. The advantage can be seen at the higher frequencies because the phase shift is much lower for HCMC. It can also be seen that the PCMC operates at the edge of instability (to achieve the same unity gain frequency); any more loop gain in the compensator makes the system oscillate. Therefore in order to make the system sufficiently stable and increase the loop gain, a relatively complex compensation network and dynamic slope compensation are required.

To test HCMC for varying operating conditions, the topology in Fig. 3 with the circuit parameters in Table $\mathrm{I}$ is simulated in SIMPLIS for a range of duty ratios and switching frequencies. The results of loop gain and phase are shown in Fig. 6 and Fig. 7 respectively. It can be seen that the phase margin stays sufficient for a wide range of operating conditions.

Apart from the inherent stability and higher bandwidth, ripple HCMC provides an extra degree of freedom: changing the current ripple. This property is exploited here by adaptively adjusting the ripple to keep the converter in soft switching and thus increase efficiency.

\section{B. Minimum dissipation}

In an application involving battery powered USN nodes, the requirement of output power can change drastically from low to high power levels and vice versa. Therefore in order to improve battery life, the boost converter must be power efficient over a wide range of output power levels. A complete characterization of different power dissipation mechanisms in 


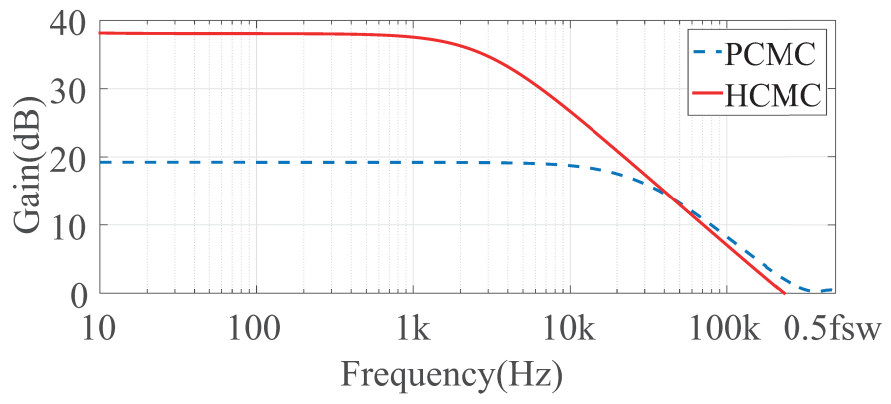

Fig. 4. Loop gain comparison of PCMC and HCMC

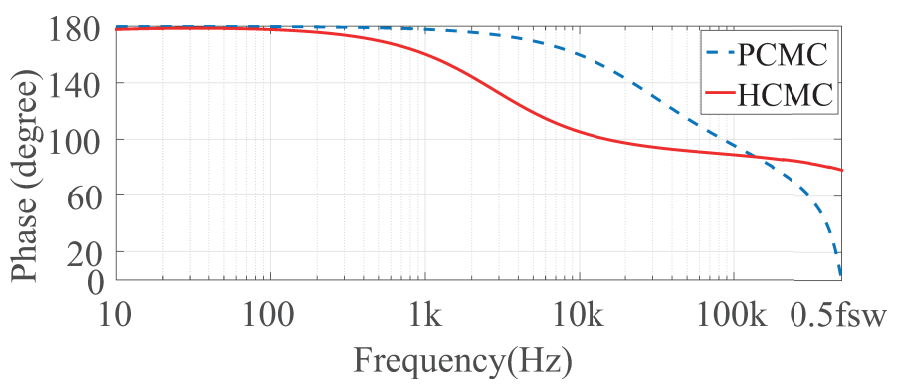

Fig. 5. Phase comparison of PCMC and HCMC

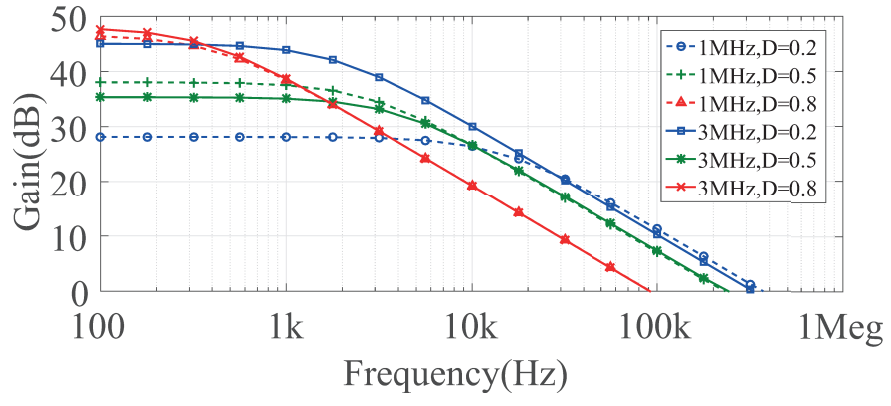

Fig. 6. Loop gain of HCMC for different duty ratios and switching frequencies

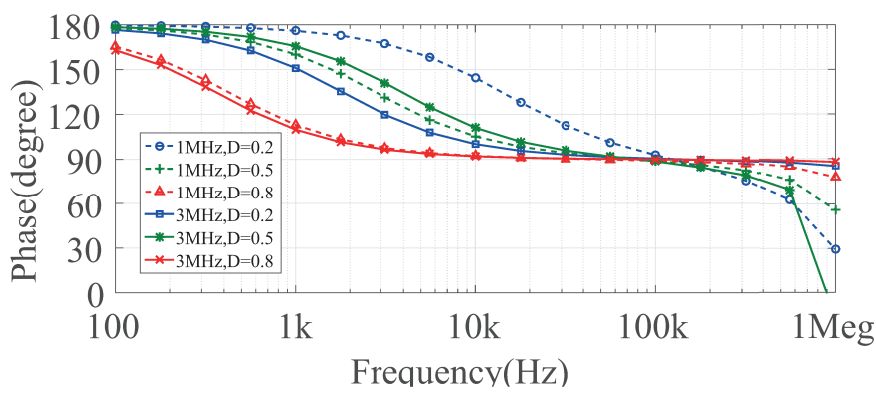

Fig. 7. Phase of HCMC for different duty ratios and switching frequencies

a class-D amplifier is given in [23]. The results show that for a high voltage class-D amplifier, minimum dissipation can be achieved by keeping the amplifier running near the soft switching boundary, where the inductor current is just enough to charge and discharge the output switching node. Therefore in order to verify the same conclusion for a boost converter, the boost converter with power stage shown in Fig. 8 is analyzed here. The output voltage of a boost converter can be expressed as:

$$
V_{\text {out }}=\frac{V_{d d}}{1-D}
$$

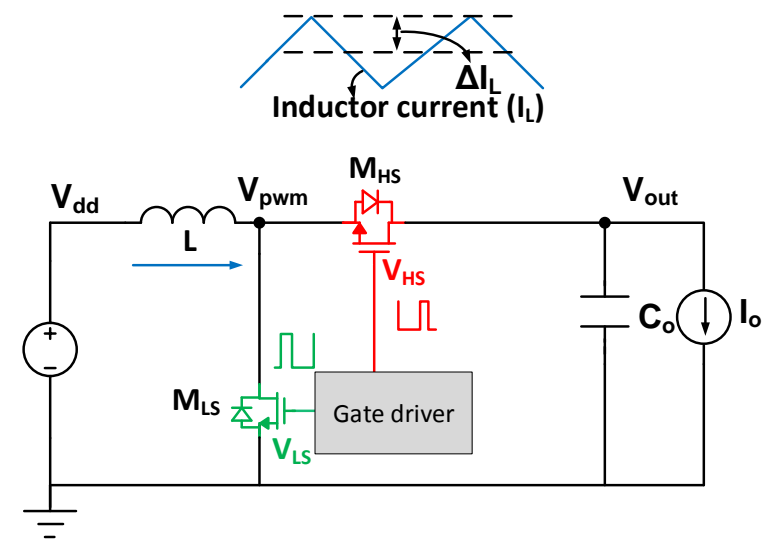

Fig. 8. A bidirectional boost converter power stage

The root mean squared inductor current $I_{L, R M S}$ is composed of a dc component $I_{L}$ and a triangle ripple component $\Delta I_{L}$. This can be expressed as [23]:

$$
I_{L, R M S}=\sqrt{I_{L}{ }^{2}+\frac{\Delta I_{L}{ }^{2}}{12}}
$$

The dc component of the inductor current $I_{L}$ depends on the output current $I_{o}$ and duty ratio (D):

$$
I_{L}=\frac{I_{O}}{1-D}
$$

the ripple of the inductor current $\Delta I_{L}$, is given by:

$$
\Delta I_{L}=\frac{V_{d d} * D}{2 * L * f_{s w}}
$$

The total dissipation $\left(P_{d}\right)$ in a boost converter can be categorized into three major loss mechanisms: conduction loss $\left(P_{\text {cond }}\right)$ due to the inductor current $\left(I_{L, R M S}\right)$, gate-driver loss $\left(P_{g}\right)$ caused by charging and discharging the gate capacitance of the power transistors and switching loss $\left(P_{s w}\right)$ associated with charging and discharging of the output parasitic capacitances of the power transistors at the PWM node. For high voltage applications, the dominant losses are the switching losses. As shown in Fig. 9, the switching loss $\left(P_{s w}\right)$ based on falling switching transition (also valid for rising transitions) can be categorized into one of the following categories:

- Hard switching loss: The inductor current cannot discharge the PWM node as shown in Fig. 9a.

- Partial soft switching: The inductor current is not large enough to completely discharge the PWM node during dead time as shown in Fig. 9b.

- Complete soft switching: The inductor current is enough to completely discharge the PWM node as shown in Fig. 9c.

In order to verify if the minimum dissipation can be achieved at the soft switching boundary, a comparison of the transistor-level power dissipation simulation with the analytical model presented in [23] can be made. Therefore the output 


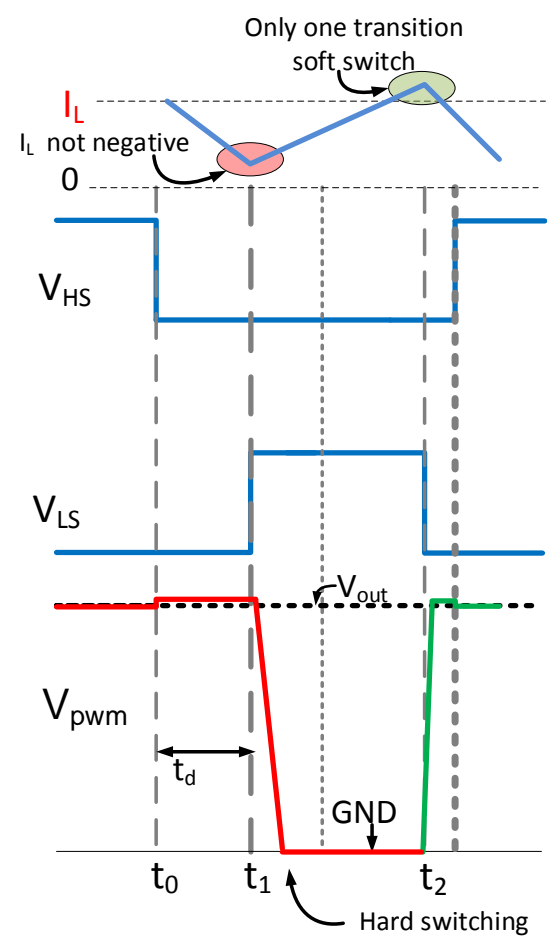

(a) one hard-switching transition

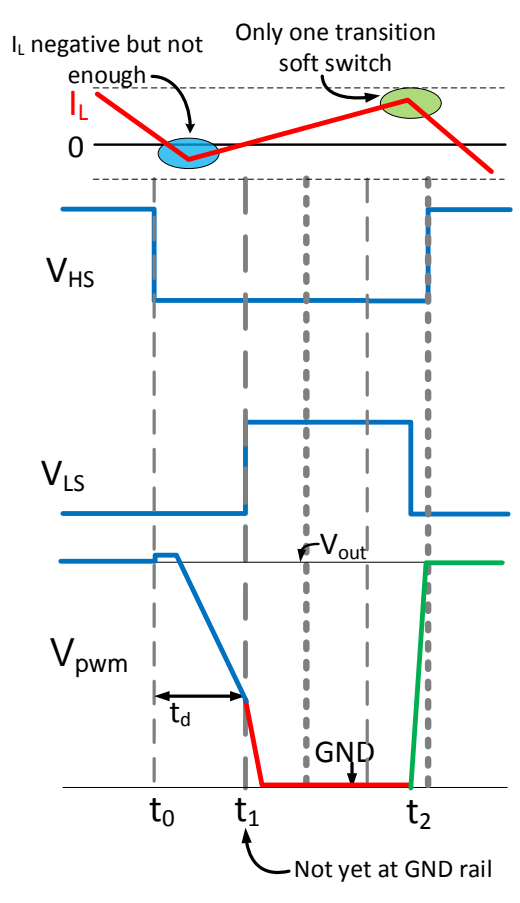

(b) partial soft switching transition

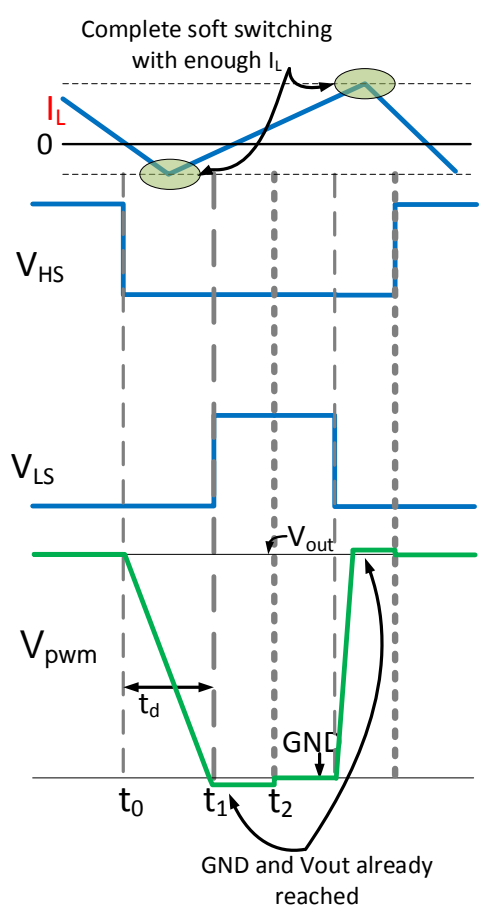

(c) complete soft switching transition

Fig. 9. Illustration of different switching conditions from hard-switching to complete soft switching

TABLE II

CIRCUIT PARAMETERS FOR DISSIPATION ANALYSIS

\begin{tabular}{cc}
\hline \hline Parameters & Values \\
\hline Power mosfet model & IRFL014 \\
Gate driver model & LTC4446 \\
Diode model $(\mathrm{D})$ & $1 \mathrm{~N} 5819$ \\
Boot strap capacitance $\left(\mathrm{C}_{\text {boot }}\right)$ & $0.1 \mu \mathrm{F}$ \\
Duty ratio $(\mathrm{D})$ & 0.5 \\
Inductor $(\mathrm{L})$ & $2 \mu \mathrm{H}$ \\
Supply voltage $\left(\mathrm{V}_{\mathrm{dd}}\right)$ & $9 \mathrm{~V}$ \\
Driver voltage $\left(\mathrm{V}_{\mathrm{cc}}\right)$ & $9 \mathrm{~V}$ \\
On resistance $\left(\mathrm{r}_{\mathrm{on}}\right)$ & $250 \mathrm{~m} \Omega$ \\
Gate charge $\left(\mathrm{Q}_{\mathrm{iss}}\right)$ & $8 \mathrm{nC}$ \\
Output charge $\left(\mathrm{Q}_{\mathrm{oss}}\right)$ & $6 \mathrm{nC}$ \\
Output capacitance $(\mathrm{Co})$ & $10 \mu \mathrm{F}$ \\
Dead time $\left(\mathrm{t}_{\mathrm{d}}\right)$ & $80 \mathrm{nsec}$ \\
Load current $\left(\mathrm{I}_{\mathrm{o} 1}\right)$ & $50 \mathrm{~mA}$ \\
Load current $\left(\mathrm{I}_{\mathrm{o} 2}\right)$ & $400 \mathrm{~mA}$
\end{tabular}

power stage shown in Fig. 8 with circuit parameters in Table II is simulated with two different output power conditions for a range of switching frequencies (to vary the inductor current ripple).

The comparison of the analytical model and circuit simulation is shown in Fig. 10 and Fig. 11 for an output current $\left(I_{\text {out }}\right)$ of $50 \mathrm{~mA}$ and $400 \mathrm{~mA}$ respectively.

For low output power as shown in Fig. 10, the dissipation is mainly due to conduction losses at low switching frequency, due to the large current ripple. As the switching frequency is

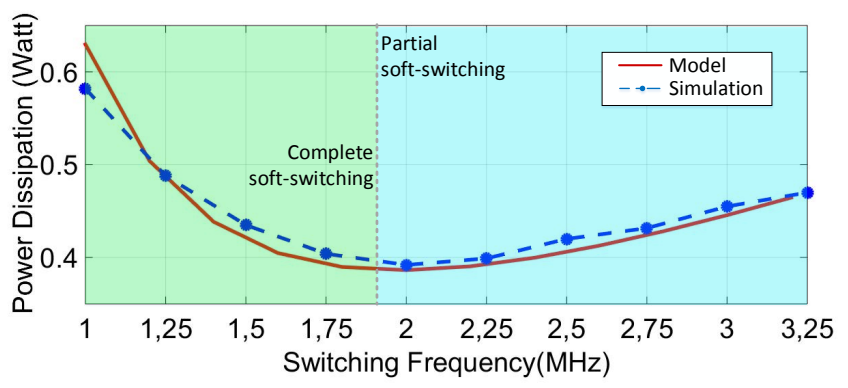

Fig. 10. Minimum power loss Vs switching frequency for fixed $\mathrm{Vo}=24 \mathrm{~V}$ and $\mathrm{Io}=50 \mathrm{~mA}$

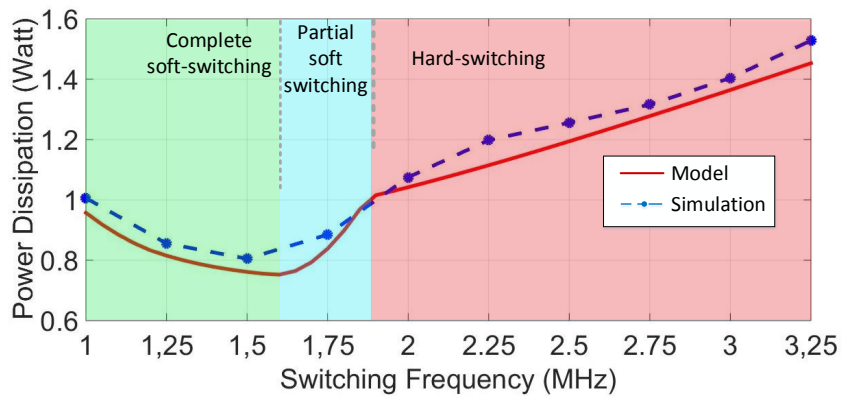

Fig. 11. Minimum power loss Vs switching frequency for fixed $\mathrm{Vo}=24 \mathrm{~V}$ and $\mathrm{Io}=400 \mathrm{~mA}$ 


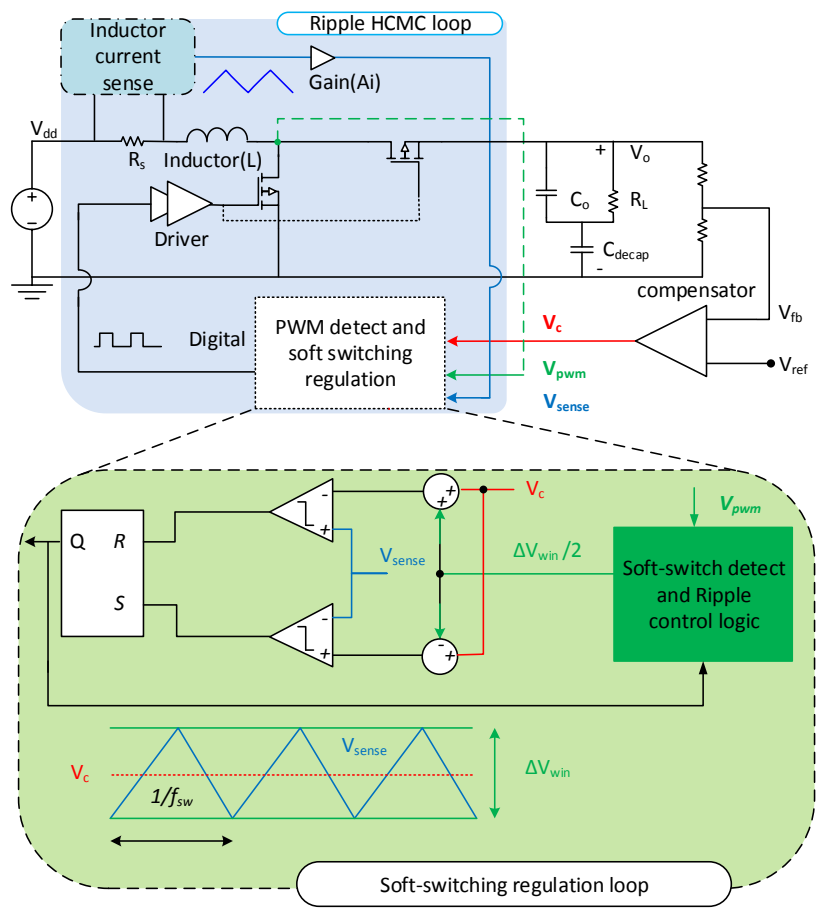

Fig. 12. HCMC based boost converter with soft switch regulation loop

increased, the conduction losses reduce, the converter stays fully soft switching and a minimum dissipation point is achieved. Further increasing the switching frequency results in partial soft switching transitions making switching loss start to increase. For high output power as in Fig. 11, the trend is similar. The minimum dissipation point is achieved at a lower switching frequency because a larger inductor current ripple is necessary to keep $I_{L}$ bidirectional at the switching instants.

Compared to hard switching, complete soft switching requires a reverse inductor current that can be considered an extra loss. However, in high voltage applications, the $C V^{2}$ losses of charging parasitic capacitances are higher than the extra loss as a result of the reverse inductor current, as can be seen in Fig. 11.

These results show that also for a high voltage boost converter power stage, the minimum dissipation occurs at the boundary of soft switching and partial soft switching. For the case of simplicity the inductor core loss is ignored in the comparison above. Inductor core loss increases the total dissipation, however as shown in [23] the minimum dissipation still occurs very close to the soft switching boundary. Therefore by changing the hysteretic window in HCMC as function of $I_{o}$, the current ripple can directly be controlled and the switching frequency can be brought to this point of minimum dissipation.

\section{Soft switching regulation loop}

Based on the results in section II-B, our proposed scheme uses a soft switching regulation loop as shown in Fig. 12 to reduce power dissipation, by adaptively changing the magnitude of the current ripple. This results in optimum power efficiency over wide range of output power levels for the HCMC based boost converter.

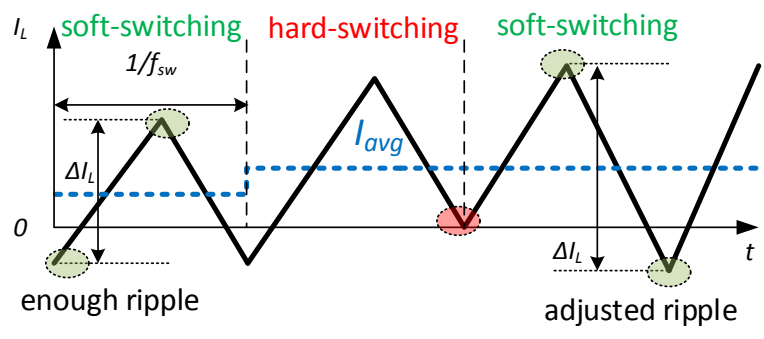

Fig. 13. The regulation of soft switching transitions

In order to make the converter run in soft switching, detection of the switching transitions is a first step. Depending on the magnitude and direction of the inductor current at the switching instant, switching of the $V_{\text {pwm }}$ node can be made lossless. As was shown in Fig. 9c, complete soft switching can occur when the inductor current is bi-directional and can charge/discharge the parasitics at $V_{\text {pwm }}$ to $V_{\text {out }}$ and $G N D$ respectively, making both the rising and falling transitions soft switching. By observing the $V_{p w m}$ node during $t_{d}$ it can be detected if a transition is soft switching: if the PWM node reaches the opposite supply rail within the dead time, the transition is lossless.

The soft switching regulation loop that we use can be best understood with the help of Fig. 13 which shows a step increase of the average inductor current. The moment the average inductor current is increased, one of the transitions becomes hard-switching; this triggers the soft switching regulation loop to increase the hysteretic window, causing the inductor current ripple $\left(\Delta I_{L}\right)$ to increase and move the converter back to soft switching transitions. This way it can track the highest efficiency over a wide range of output power levels.

Although the HCMC loop and the soft switching loop together determine the PWM signal, the loops are basically independent. Fig. 12 shows that the hysteretic window is determined by adding and subtracting $1 / 2 \Delta V_{\text {win }}$ from the error voltage $V_{c}$, generating the inductor current switching points $V_{\text {peak }}$ and $V_{\text {valley }}$. Therefore, these are symmetric around the error voltage $V_{c}$. So when the ripple (represented by $\Delta V_{\text {win }}$ ) changes, $V_{\text {peak }}$ and $V_{\text {valley }}$ change, but the average stays the same. Although the gain and phase of the HCMC loop change somewhat due to the changing switching frequency (as illustrated in Fig. 6 and Fig. 7), the duty cycle and the average inductor current stay the same and the output voltage regulation is (in first order) not disturbed. Hence the HCMC loop and $f_{s w}$ regulation loop are largely independent, preventing instability [27].

\section{System AND CiRCUit IMPLEMENTATION}

The proposed implementation of the topology is shown in Fig. 14. The system is realized on a PCB using an external power stage and the control is realized on chip. The nonoverlapping gate driver signals are generated internally for the 


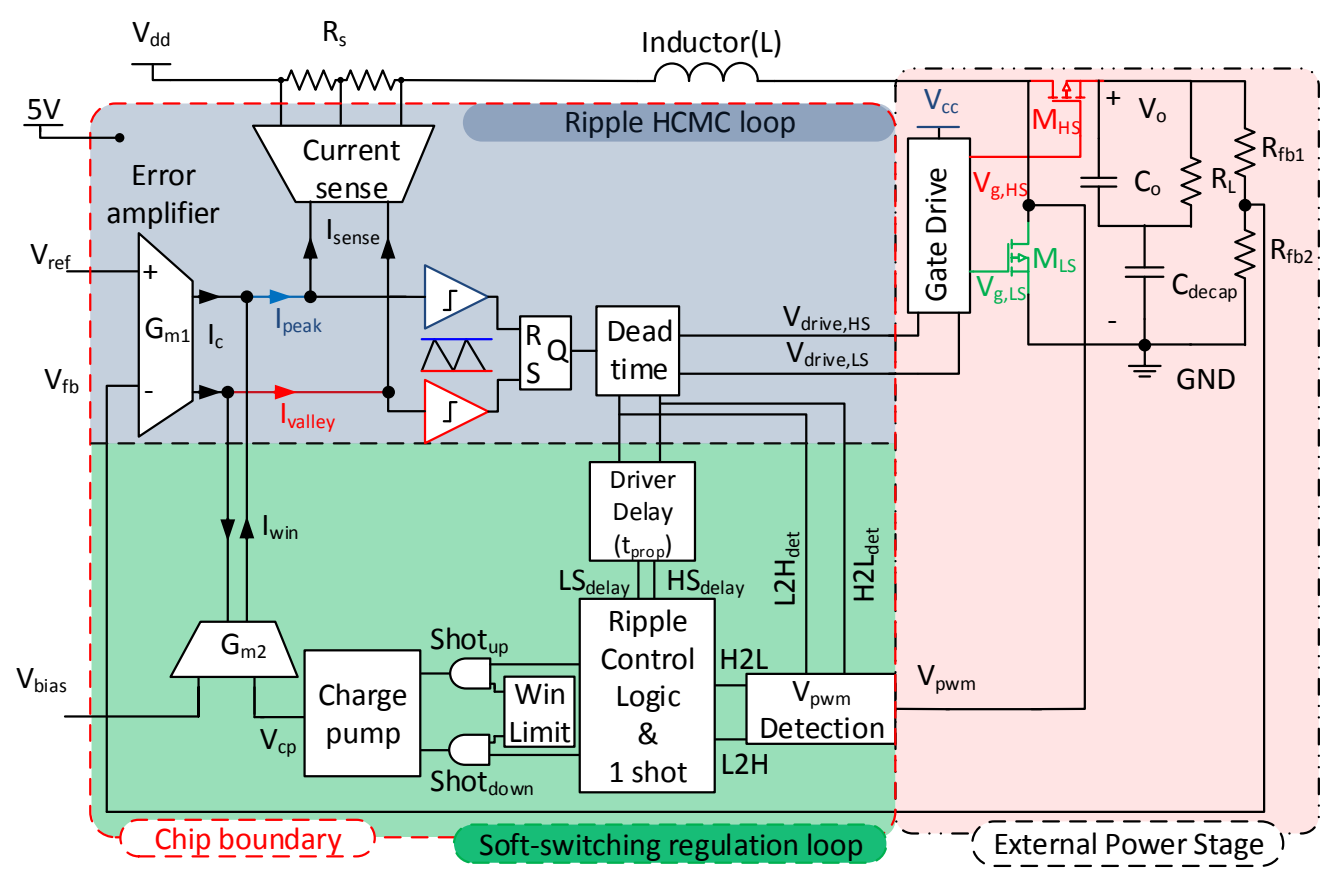

Fig. 14. System overview of HCMC based boost converter with soft switching regulation

external gate driver IC. The chip circuitry is mainly divided into the ripple HCMC loop and the soft switching regulation loop. Due to the ease of adding and subtracting currents, the HCMC loop implementation is realized in the current domain.

\section{A. $H C M C$ regulation}

The HCMC loop is responsible for making sure the output voltage $V_{o}$ signal tracks the external reference signal $V_{\text {ref }}$ using a negative feedback loop. The actual implementation of the transconductor is shown in Fig. 15. The on-chip CurrentSense (CS) transconductor produces two copies of $I_{\text {sense }}$, a scaled version of $I_{L}$, by translating the voltage across the sensing resistor $R_{s}$.

The transconductor $G_{m 1}$ generates two copies of the desired control current $I_{c}$ (current representation of $V_{c}$ in Fig. 12), whereas the transconductor $G_{m 2}$ produces the relevant window current $I_{\text {win }}$ (current representation of $V_{\text {win }}$ in Fig. 12) to set the desired $f_{s w}$. The implementation of both transconductors is identical using source degeneration for better linearity, only the degeneration resistors are different and one of the output currents of $G_{m 2}$ is reversed because it must be subtracted from $I_{c}$. To avoid a negative window the charge pump voltage $V_{c p}$ is always greater than $V_{\text {bias }}$. The peak and valley current comparators are implemented as inverters.

\section{B. Current sensing}

In all current mode control based topologies, current sensing is a fundamental step. Several techniques have been reported in literature to implement on-chip current sensors [28]-[31]. For HCMC the complete inductor current needs to be sensed, therefore for maintaining simplicity and accuracy, the choice of an off-chip sense resistor $R_{s}$ is made. The value of $R_{s}$

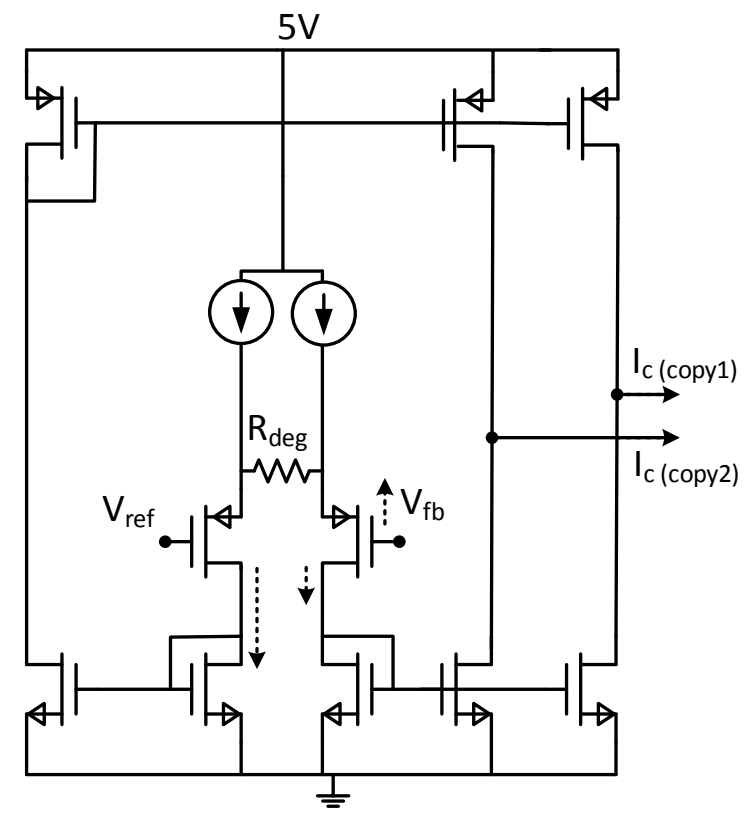

Fig. 15. Implementation of transconductor $G_{m 1}$

is chosen to be four times smaller than $R_{o n}$ of the external power transistor to keep conduction losses low.

To reduce distortion in $V_{o}$, a linear current sensing scheme is proposed in Fig. 16. The circuit is designed to handle commonmode voltages near $V_{d d}$ and is implemented differentially. The gate voltage of the input transistors $M_{1-4}$ is set by bias transistor $M_{b}$. The cascode transistor $M_{\text {cascode }}$ helps to improve current matching. The $M_{H V \text { protect }}$ transistors clamp the LVNMOS gate voltage during an over-current situation. 


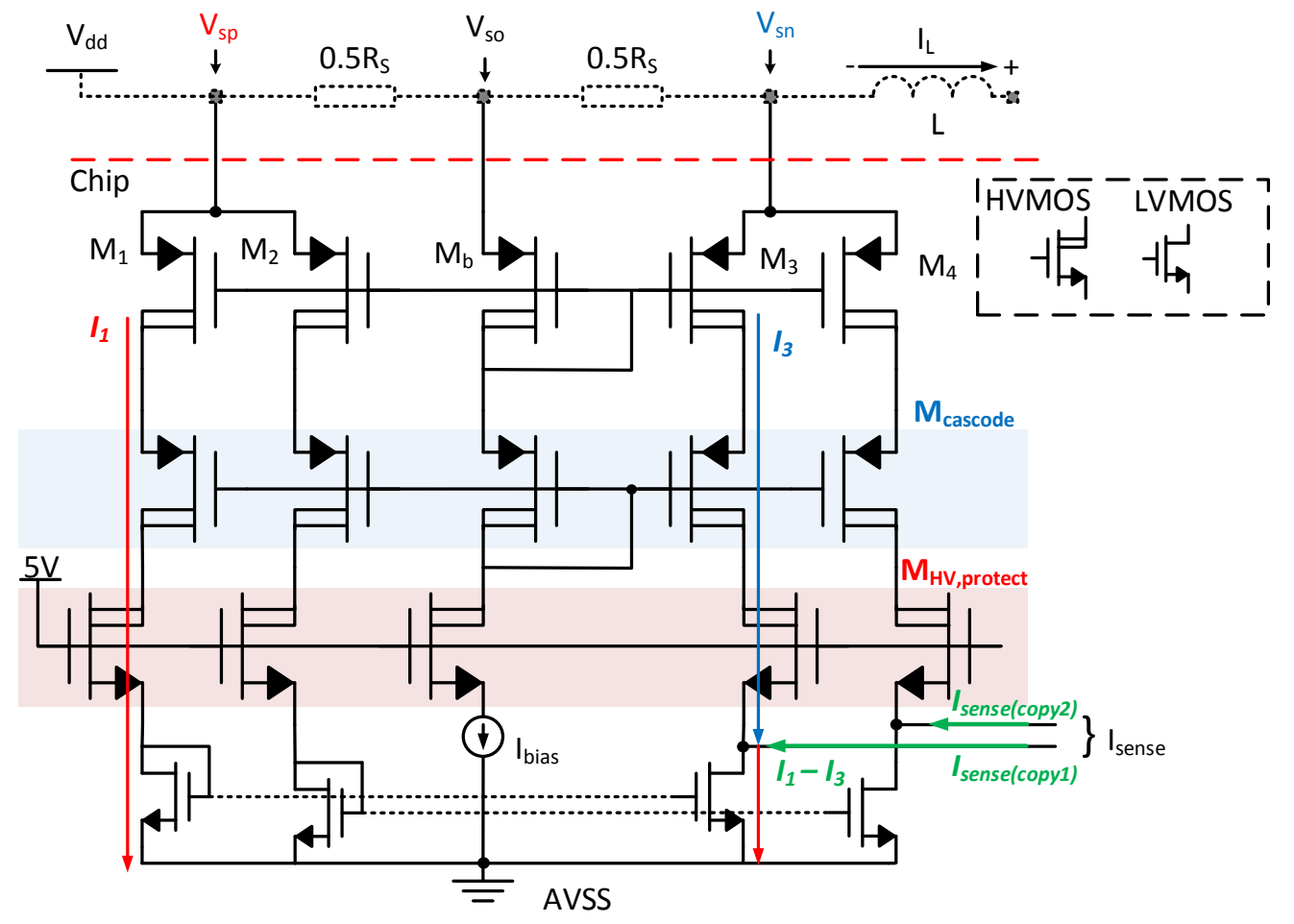

Fig. 16. High side current sense circuit

During an increase in $I_{L}$ as shown in Fig. 16, the gatesource voltage of both $M_{1}$ and $M_{2}$ increase while the gatesource voltage of $M_{3}$ and $M_{4}$ decreases. Hence the current $I_{1}$ increases and $I_{3}$ decreases. The difference current $I_{\text {sense }}$ is thus equal to the inductor current $I_{L}$ scaled by $R_{s}$ and the transconductance (gm) of $M_{1}$ and $M_{3}$. The advantage comes from the fact that while $\mathrm{gm}$ is non-linear, the difference of currents cancels the (dominant) second order non-linearity of $\mathrm{gm}$. Therefore, linearity is better compared to a differential pair, where the sum $I_{1}$ and $I_{3}$ would be constant. The maximum non-linearity of the simulated current sense is $2.6 \%$ of full scale. Small deviations in the sensed inductor current are no problem because the external loop tracks the average current and adjusts it until the average current is correct. In total two replica currents are generated for peak and valley level detection as explained in Fig. 15 earlier.

\section{Soft switching regulation}

The soft switching regulation loop shown in Fig. 14 works by observing $V_{p w m}$ at the end of the dead time $t_{d}$. This information is passed to the ripple control logic to determine if the ripple needs to be increased or decreased in order to keep the converter running in soft switching. Based on this decision, the ripple control logic drives the charge pump/loop filter with an up/down single shot pulse. If the ripple needs to be increased, the charge pump increase $V_{c p}$ with a step $\Delta V_{c p}$ and vice versa.

Due to the fact that we use an external power stage, the signals $V_{g, H S}$ and $V_{g, L S}$ generated by the chip suffer from propagation delay introduced by the external driver IC. Hence to satisfy the timing requirements for internal logic, a replica delay $t_{\text {prop }}$ is added to the internal signals in the ripple control logic block and must be set to match the external driver delay.

Depending on the output power level, the regulation loop adjusts $f_{s w}$ in order to maintain soft switching. The minimum $f_{s w}$ is chosen to be $1 \mathrm{MHz}$ dictated by inductor size, distortion and point of hard switching. Similarly the maximum $f_{s w}$ must be limited to approximately $3.2 \mathrm{MHz}$ due to the external power stage propagation delay, distortion caused by dead time and gate driver dissipation. The $f_{s w}$ limits are externally set by specifying the window limits; the window limit block monitors $I_{\text {win }}$ and disables the ripple control logic if needed.

In normal operation during steady state the regulation loop oscillates around soft and partial soft switching transitions every alternate switching cycle. The main time constant in the loop, however, is set by the loop filter, ensuring a dominant first order behaviour of the loop gain. Therefore in response to sudden increase/decrease in output power, the regulation loop doesn't abruptly change the ripple.

The step size $\Delta V_{c p}$ of the charge pump is set to $20 \mathrm{mV}$, equivalent to a $110 \mathrm{~mA}$ change in inductor current, which is based on the required tracking speed of the loop. In the proposed design, the tuning window of the charge pump voltage is $350 \mathrm{mV}$, meaning the loop can adapt from minimum to maximum inductor current in 18 switching periods. With an average switching frequency of $2 \mathrm{MHz}$ this results in a $30 \mathrm{kHz}$ full-power bandwidth. 


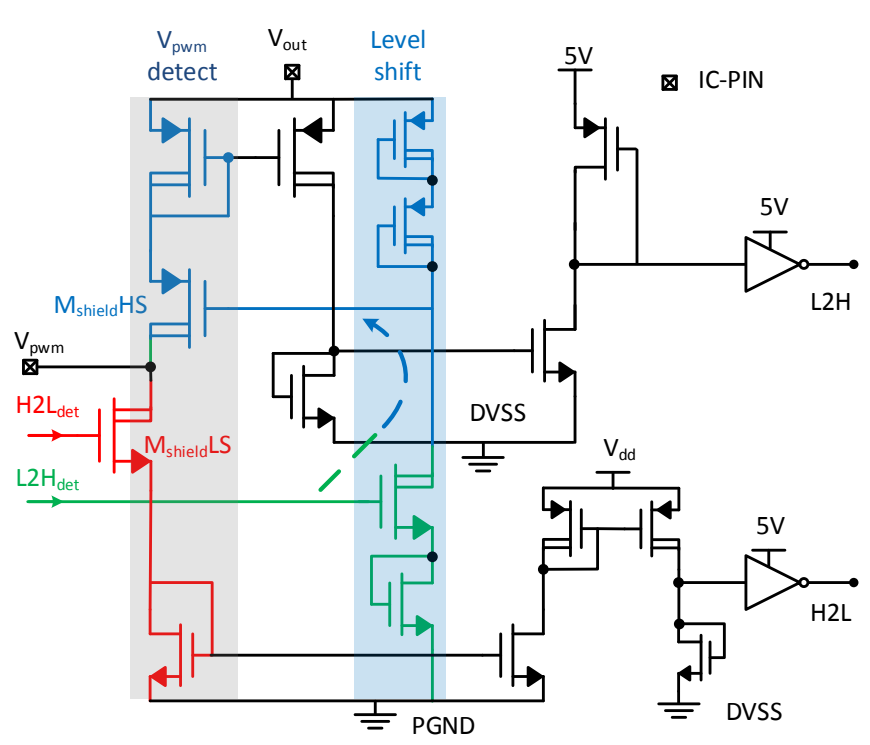

Fig. 17. Soft switching detection circuit

\section{D. $V_{\text {pwm }}$ detect and ripple control}

The $V_{\text {pwm }}$ detection circuit is shown in Fig. 17. When $H 2 L_{\text {det }}$ or $L 2 H_{\text {det }}$ is high, it detects if $V_{\text {pwm }}$ has reached the corresponding supply rail within the dead time $t_{d}$. Since the $V_{g, H S}$ driver signal is level shifted by the driver IC for proper operation, $L 2 H_{\text {det }}$ must also be level shifted to turn on $M_{\text {shield }} H S$ transistor, as shown in Fig. 17. The $H 2 L$ detection is communicated via a current mirror near $V_{d d}$ to isolate the severe ground bounce on the power ground. The detection information is passed to the ripple control logic shown in Fig. 18. The ripple control logic checks if both rising and falling transitions of the $V_{p w m}$ node are soft switching, triggering the corresponding DN pulse. If any one of the $V_{p w m}$ transitions is not finished within $t_{d}$, the UP pulse is triggered. These UP/DN pulses are passed on to the charge pump at the end of each switching cycle resulting in increase/decrease in the current ripple. The charge pump is timed by a one shot circuit to increase and decrease the voltage in steps at the input of the transconductor.

\section{Measurements}

The proposed HCMC based boosting amplifier with soft switching regulation is implemented on a PCB as shown in Fig. 19, combining an external power stage and the proposed chip. The chip is implemented in a $60 \mathrm{~V} 0.25 \mu \mathrm{m}$ high voltage CMOS process with a size of $3 \mathrm{~mm} \times 3 \mathrm{~mm}$ and is shown in Fig. 20. The performance and component parameters are summarized in Table III. For the chip implementation the analog and digital sections are separated in the layout to avoid switching noise. Similarly the external power stage switching current loop is separated from the analog signal path, to reduce the effect of ground bounce. For start-up operation, the soft switching loop is initially disabled by an enable/disable pin and an initial charge pump voltage of $V_{c p}=1.55 \mathrm{~V}$ is applied externally. After the amplifier reaches steady state operation, the soft switching loop is enabled.

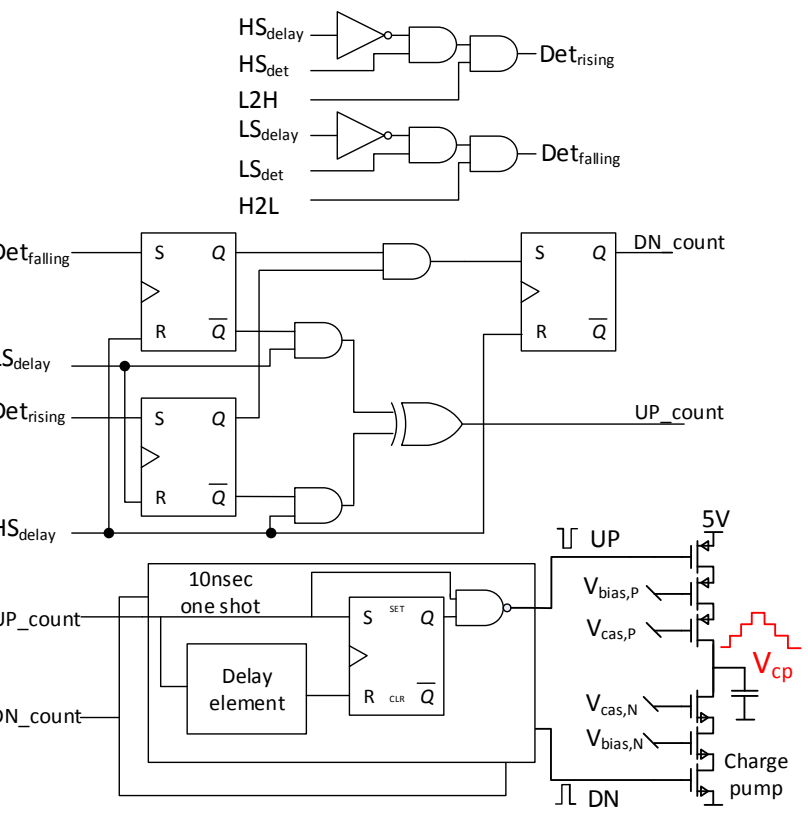

Fig. 18. Ripple control logic

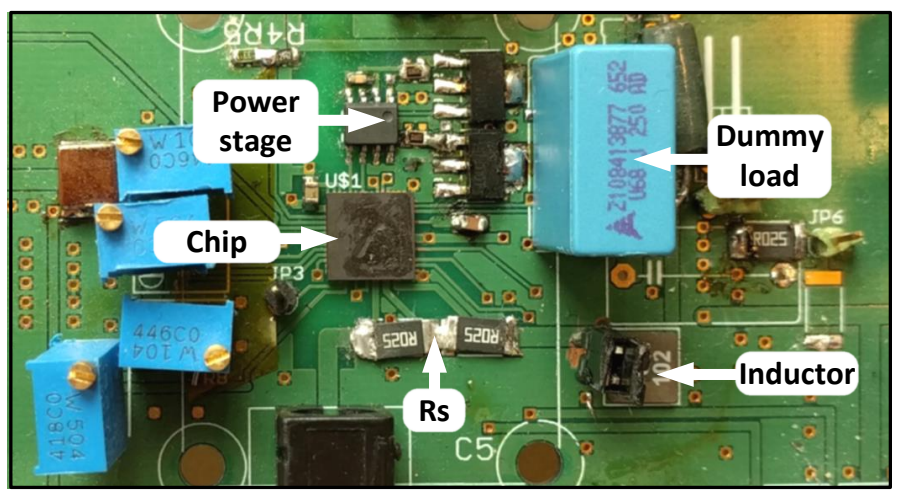

Fig. 19. Implemented PCB for the amplifier

Fig. 21 shows the boosted output voltage, measured across the load for a $30 \mathrm{kHz}$ sine wave. The output shows a $38 \mathrm{Vpp}$ signal with a supply voltage of $9 \mathrm{~V}$. Although the technology supports $60 \mathrm{~V}$, the maximum output voltage is limited to $50 \mathrm{~V}$ because at high switching frequencies the dead time limits the maximum boosting ratio. Also, some of this headroom is used for $r_{o n}$ losses.

Fig. 22 and Fig. 23 present a comparison between the operation of the amplifier at two output powers. For the first case where the amplifier is driven by a high swing input signal, the inductor current ripple is increased to make the converter run near the soft switching boundary. When the input voltage signal decreases, the inductor current ripple decreases resulting in optimum operation.

As the load is dominantly capacitive at the desired signal frequency of $30 \mathrm{kHz}$, the processed output power $\left(P_{\text {out }}\right)$ is apparent power. Hence the measured efficiency is calculated as:

$$
\eta=\frac{P_{\text {out }}}{P_{\text {out }}+P_{d}}
$$




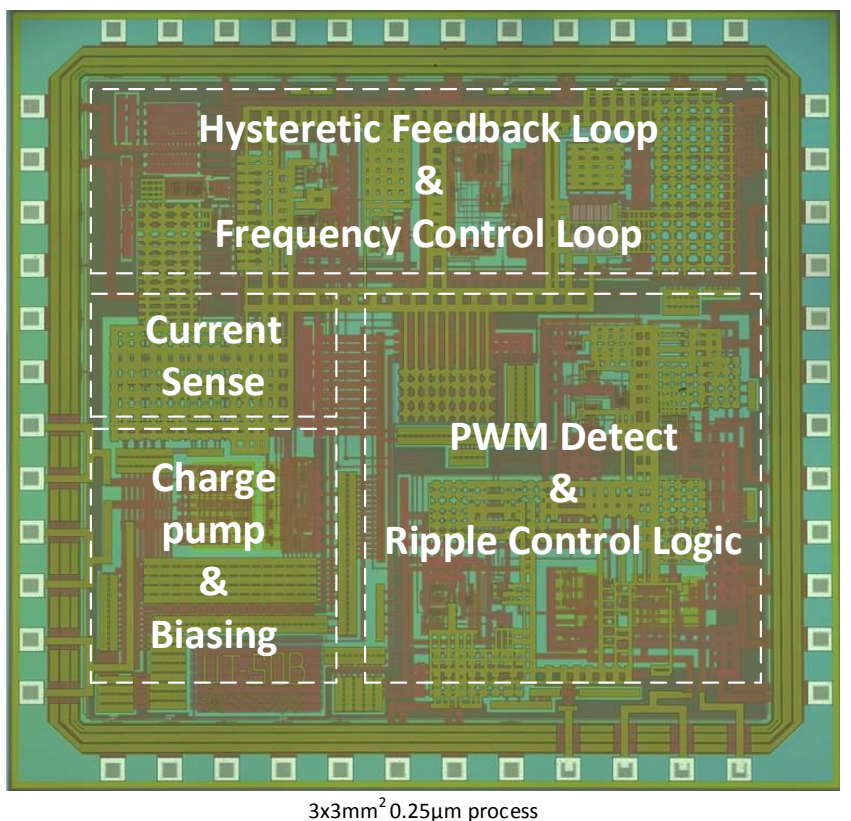

Fig. 20. Chip micrograph

TABLE III

Performance ANd Components Summary

\begin{tabular}{cc}
\hline \hline Parameters & Values \\
\hline Technology & $0.25 \mu \mathrm{m}$ HVCMOS \\
Driver IC & LM5101C \\
Power transistors & NDT3055 \\
C $_{\text {boot }}$ & $0.1 \mu \mathrm{F}$ \\
Inductor $(\mathrm{L})$ & $2 \mu \mathrm{H}$ \\
Supply voltage $\left(\mathrm{V}_{\mathrm{dd}}\right)$ & $9 \mathrm{~V}$ \\
Driver voltage $\left(\mathrm{V}_{\mathrm{cc}}\right)$ & $9 \mathrm{~V}$ \\
IC voltage & $5 \mathrm{~V}$ \\
On resistance $\left(\mathrm{r}_{\mathrm{on}}\right)$ & $100 \mathrm{~m} \Omega$ \\
Output capacitance $(\mathrm{Co})$ & $0.47 \mu \mathrm{F}$ \\
Decoupling capacitor $\left(\mathrm{C}_{\mathrm{dec}}\right)$ & $50 \mu \mathrm{F}$ \\
Switching Freq $\left(\mathrm{f}_{\mathrm{sw}}\right)$ & $1 \mathrm{MHz}-3.2 \mathrm{MHz}$ \\
Signal Freq $\left(\mathrm{f}_{\text {sig }}\right)$ & $30 \mathrm{kHz}$ \\
$* \mathrm{R}_{\mathrm{L}}$ & $1 \mathrm{k} \Omega$ \\
Dead time $\left(\mathrm{t}_{\mathrm{d}}\right)$ & $80 \mathrm{nsec}$ \\
Die Size & $85 \% @ 20 \mathrm{VA}$ \\
Maximum Power Efficiency $(\eta)$ & $3 \mathrm{~mm} \times 3 \mathrm{~mm}$ \\
\hline $\mathrm{R}$ & \\
\hline
\end{tabular}

Where $P_{\text {out }}$ is measured as $V_{\text {out,rms }} * I_{\text {out }, \text { rms }}$ (VA) and $P_{d}$ is the total amplifier power dissipation, including external power stage and control circuits. The measured efficiency of the boosting amplifier for a $30 \mathrm{kHz}$ sine wave as a function of $P_{\text {out }}$ is shown in Fig. 24 for both fixed and adaptive $f_{s w}$. $P_{\text {out }}$ is varied by changing the amplitude of the output signal. Since the proposed scheme tunes itself to achieve minimum power loss, the effectiveness of the scheme is compared to two fixed $1 \mathrm{MHz}$ and $3.2 \mathrm{MHz} f_{s w}$ modes. Fig. 24 clearly shows that the scheme tracks the best efficiency across the whole output power range as compared to the low and high switching

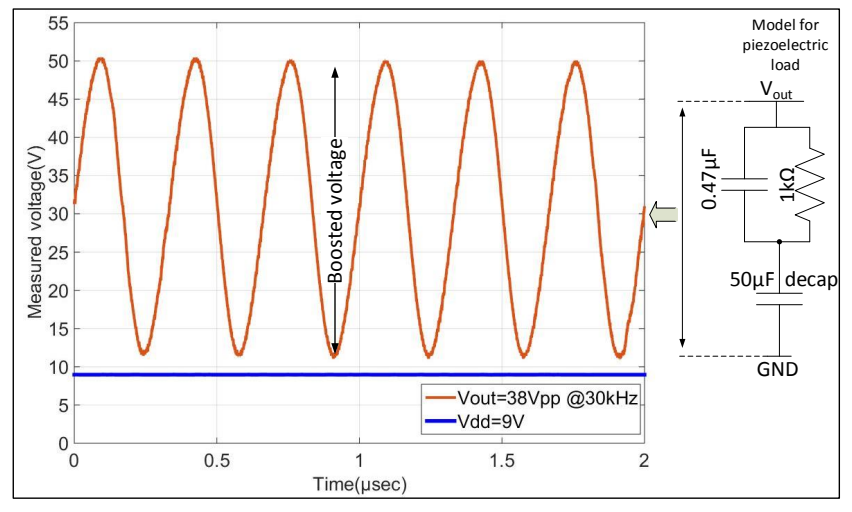

Fig. 21. Time domain waveform of boosted output signal (red) generated at $30 \mathrm{kHz}$ across $V_{\text {out }}$ and GND with an input supply of $9 \mathrm{~V}$

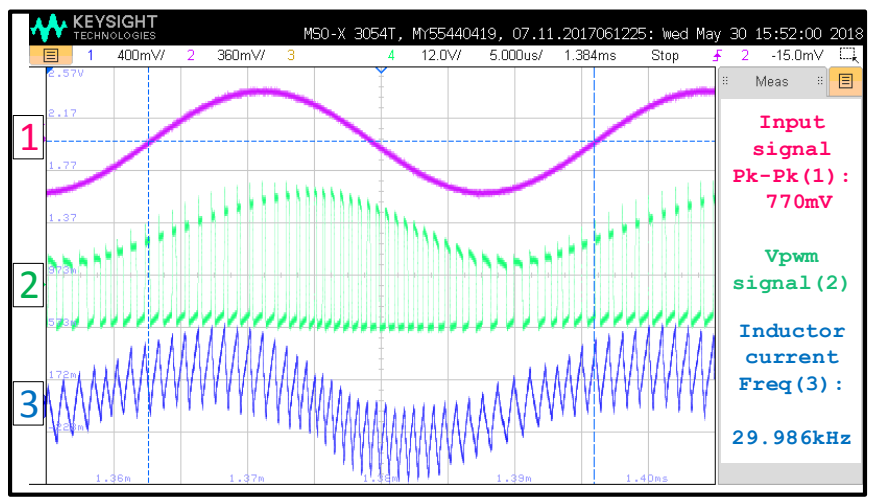

Fig. 22. Time domain waveform of PWM (green) signal generated at $30 \mathrm{kHz}$ across $V_{p w m}$ and GND with inductor current $I_{L}$ (blue)

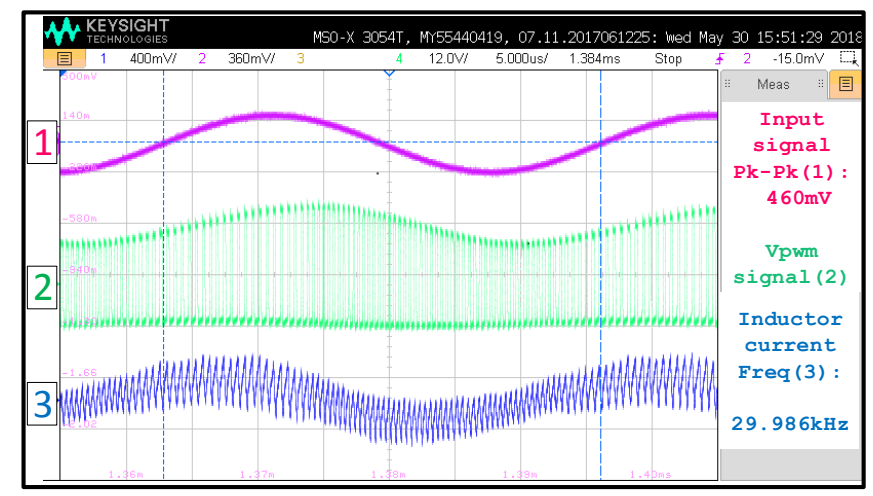

Fig. 23. Time domain waveform of PWM (green) signal generated at $30 \mathrm{kHz}$ across $V_{p w m}$ and GND with inductor current $I_{L}$ (blue) 


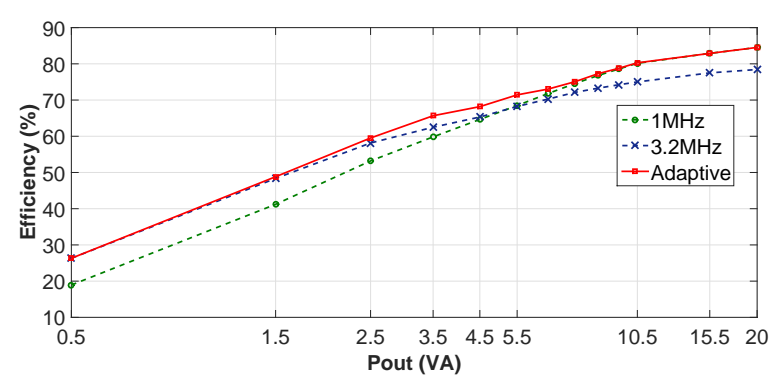

Fig. 24. Efficiency measurements for adaptive and fixed $f_{s w}$ as a function of output power at $30 \mathrm{kHz}$ input signal.

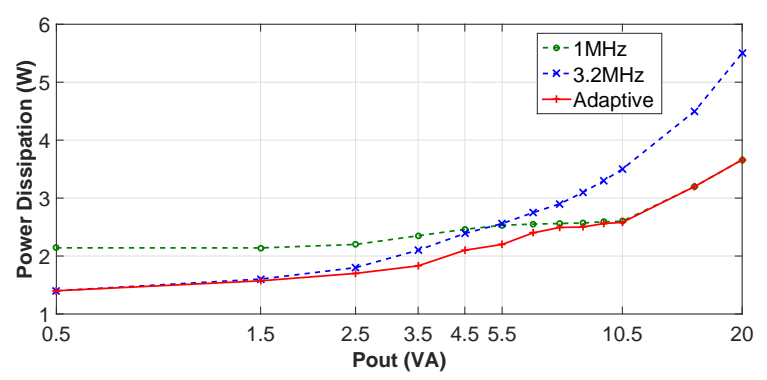

Fig. 25. Power dissipation measurements for adaptive and fixed $f_{s w}$ as a function of output power at $30 \mathrm{kHz}$ input signal.

modes.

Fig. 25 shows a comparison of the power dissipation $P_{d}$ of the adaptive $f_{s w}$ regulation with fixed $f_{s w}$ conditions. At low output power, the amplifier regulates itself to $3.2 \mathrm{MHz}$ switching frequency and at high power it regulates itself to $1 \mathrm{MHz}$ switching frequency.

For the case of minimum output power, the soft switching regulation improves the efficiency from $18.9 \%$ to $27 \%$ by dissipating $35 \%$ less power compared to switching at a fixed $1 \mathrm{MHz}$. The dissipation at low output power is mainly dominated by fixed dissipation sources independent of load current, like static currents, gate driver losses and other capacitive losses. In case of peak output power, the efficiency is improved from $78 \%$ to $84 \%$ by dissipating $33 \%$ less power compared to switching at a fixed $3 \mathrm{MHz}$. This improvement is largely independent of the signal frequency as the soft switching loop is fast enough to track a $30 \mathrm{kHz}$ signal, so lower frequency signals will be quasi static in comparison.

The system achieves a THD+N of $0.6 \%$ at $1 \mathrm{kHz}$ and $5 \%$ at $30 \mathrm{kHz}$ with a $40 V_{p p}$ sinusoidal output signal as shown in Fig. 26 and Fig. 27 respectively.

$\mathrm{THD}+\mathrm{N}$ of the amplifier is also examined as a function of output voltage swing in Fig. 28. In addition the amplifier's distortion is compared with adaptive and fixed $f_{s w}$. THD+N of a hysteretic based boost converter depends on several factors. Apart from the inherent boost converter non-linearity, contributing effects are noise, the influence of $f_{s w}$ on the loop gain [34], asymmetric rise and fall time of the $V_{\text {pwm }}$ node [23] and the effect of fixed dead time at high $f_{s w}$ [35]. The exact contribution of each effect to THD+N, however, is difficult to predict.

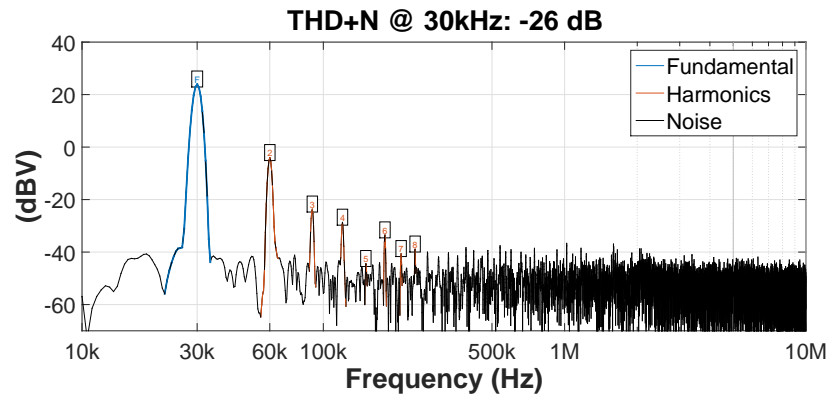

Fig. 26. Spectrum plot of $30 \mathrm{kHz} 40 V_{p p}$ sine generated across the load with $9 \mathrm{~V}$ input voltage

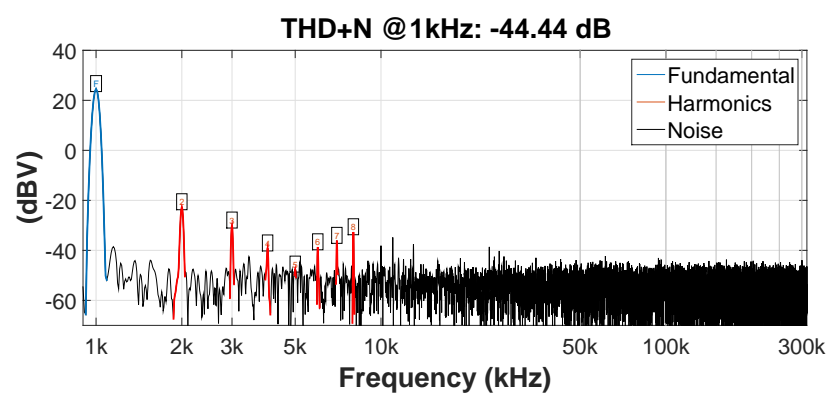

Fig. 27. Spectrum plot of $1 \mathrm{kHz} 40 V_{p p}$ sine generated across the load with $9 \mathrm{~V}$ input voltage

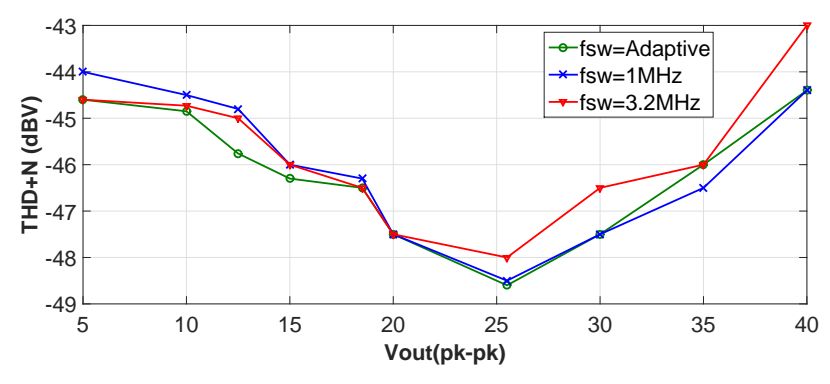

Fig. 28. $T H D+N$ measurement results comparison with $f_{\text {sig }}=1 \mathrm{kHz}$, $V_{d d}=9 \mathrm{~V}$, for adaptive $f_{s w}$ and fixed $f_{s w}$ of $1 \mathrm{MHz}$ and $3.2 \mathrm{MHz}$

The proposed amplifier is compared in Table IV with previously reported state-of-the-art piezoelectric driver topologies. Although the topology in [16] uses a boost converter for direct signal generation, the operating bandwidth and output power are very low. The topology in [32] shows much lower efficiency with even higher distortion. The work in [23] is based on a class-D amplifier which uses a fixed supply voltage. In this case for the purpose of comparison, the real efficiency of the system is calculated based on that class-D amplifier combined with a hypothetical dc-dc boost converter with an efficiency of $90 \%$. In [33], a linear amplifier is proposed; the efficiency figures are not available but bandwidth is lower and distortion is higher. Overall, the proposed system shows higher efficiency and much higher bandwidth than previous works. 
TABLE IV

COMPARISON WITH OTHER HIGH-VOLTAGE PIEZO-DRIVER TOPOLOGIES

\begin{tabular}{|c|c|c|c|c|c|}
\hline Parameters & This work & [16] & [32] & [23] & [33] \\
\hline Technology & $0.25 \mu \mathrm{m}$ & $0.18 \mu \mathrm{m}$ & - & $0.14 \mu \mathrm{m}$ & 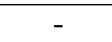 \\
\hline Topology & boosted & boosted & boosted & class-D & linear \\
\hline Load & $470 \mathrm{nF}$ & $330 \mathrm{nF}$ & $330 \mathrm{nF}$ & $23 \mu \mathrm{F}$ & $10 \mu \mathrm{F}$ \\
\hline Bandwidth (BW) & $30 \mathrm{kHz}$ & $150 \mathrm{~Hz}$ & $150 \mathrm{~Hz}$ & $300 \mathrm{~Hz}$ & $200 \mathrm{~Hz}$ \\
\hline Inductor (L) & $2 \mu \mathrm{H}$ & $100 \mu \mathrm{H}$ & $4.7 \mu \mathrm{H}$ & $100 \mu \mathrm{H}$ & N/A \\
\hline $\mathrm{V}_{\mathrm{o}} \mathrm{pp}$ & $40 \mathrm{~V}$ & $100 \mathrm{~V}$ & $100 \mathrm{~V}$ & $80 \mathrm{~V}$ & $220 \mathrm{~V}$ \\
\hline $\operatorname{Supply}\left(V_{d d}\right)$ & $9 \mathrm{~V}$ & $3.6 \mathrm{~V}$ & $3.6 \mathrm{~V}$ & $80 \mathrm{~V}$ & $220 \mathrm{~V}$ \\
\hline $\mathrm{f}_{\mathrm{sw}}$ & $1-3.2 \mathrm{MHz}$ & $\mathrm{kHz}$ range & - & $230-530 \mathrm{kHz}$ & N/A \\
\hline Efficiency & $85 \%$ & $* 82 \%$ & $* 32 \%$ & $* * 83 \%$ & - \\
\hline$\left(\mathrm{P}_{\text {out,max }}\right)$ & 20VA & $0.39 \mathrm{VA}$ & $0.39 \mathrm{VA}$ & $45 \mathrm{VA}$ & $1 \mathrm{VA}$ \\
\hline \multirow[t]{2}{*}{$\mathrm{THD}+\mathrm{N}$} & $0.6 \%-5 \%$ & $0.56 \%$ & $1.2 \%$ & $0.94 \%$ & $0.62 \%$ \\
\hline & $1 \mathrm{kHz}-30 \mathrm{kHz}$ & $150 \mathrm{~Hz}$ & $150 \mathrm{~Hz}$ & $500 \mathrm{~Hz}$ & $200 \mathrm{~Hz}$ \\
\hline
\end{tabular}

(*) Derived efficiency based on given load and dissipation conditions

(**) Derived efficiency based on class-D+boost $(\eta=90 \%)$ with same boosting ratio

\section{CONCLUSION}

This paper proposes an efficient method of generating high voltage signals for piezoelectric transducers from a single boost converter stage. By using ripple hysteretic currentmode control the boost converter can achieve high bandwidth without stability problems. Furthermore, by combining the hysteretic loop with soft switching regulation, the inductor current ripple is automatically tuned to achieve soft switching regulation over a wide range of output power. The control circuits are realized on chip and measurements show that the performance improves the state of the art by featuring higher efficiency and considerably higher bandwidth.

\section{ACKNOWLEDGMENT}

This project was funded by NWO/TTW, the Dutch Technology Foundation. The authors thank Holst Centre Netherlands for silicon donation and Stefano Stanzione for his support during layout.

\section{REFERENCES}

[1] I. F. Akyildiz, D. Pompili, and T. Melodia, "Underwater acoustic sensor networks: research challenges," Ad hoc networks, vol. 3, no. 3, pp. 257 279, 2005.

[2] M. Stojanovic, "On the relationship between capacity and distance in an underwater acoustic communication channel," ACM SIGMOBILE Mobile Computing and Communications Review, vol. 11, no. 4, pp. 34 43, 2007.

[3] K. Agbossou, J.-L. Dion, S. Carignan, M. Abdelkrim, and A. Cheriti, "Class d amplifier for a power piezoelectric load," IEEE transactions on ultrasonics, ferroelectrics, and frequency control, vol. 47, no. 4, pp. $1036-1041,2000$.

[4] M. Berkhout, "An integrated 200-w class-d audio amplifier," Solid-State Circuits, IEEE Journal of, vol. 38, no. 7, pp. 1198-1206, 2003.

[5] S. Amir, R. van der Zee, and B. Nauta, "An improved modeling and analysis technique for peak current-mode control-based boost converters," IEEE transactions on power electronics, vol. 30, no. 9, pp. 53095317, 2015.

[6] R. O. Caceres and I. Barbi, "A boost dc-ac converter: analysis, design, and experimentation," IEEE transactions on power electronics, vol. 14, no. 1, pp. 134-141, 1999.

[7] M. Prokin, "Boost bridge audio amplifier," IEEE Transactions on Consumer Electronics, vol. 47, no. 2, pp. 214-224, 2001.
[8] P. Sanchis, A. Ursæa, E. Gubía, and L. Marroyo, "Boost dc-ac inverter: a new control strategy," IEEE Transactions on Power Electronics, vol. 20, no. 2, pp. 343-353, 2005.

[9] G. B. Maizonave, M. A. E. Andersen, C. Kjærgaard, K. L. Lund, and L. B. Hansen, "Double-boost dc-ac converter with sliding-mode control for portable audio," in Audio Engineering Society Conference: 37th International Conference: Class D Audio Amplification. Audio Engineering Society, 2009.

[10] K. Jha and S. Mishra, "Large-signal linearization of a boost converter," in 2010 IEEE Energy Conversion Congress and Exposition. IEEE, 2010, pp. 4140-4144.

[11] S. K. Mishra, K. Jha, and K. D. Ngo, "Dynamic linearizing modulator for large-signal linearization of a boost converter," IEEE Transactions on Power Electronics, vol. 26, no. 10, pp. 3046-3054, 2011.

[12] V. Michal, "Modulated-ramp pwm generator for linear control of the boost converter's power stage," IEEE Transactions on Power Electronics, vol. 27, no. 6, pp. 2958-2965, 2012.

[13] T. H. Birch, D. Nielsen, A. Knott, and M. A. Andersen, "Predistortion of a bidirectional cuk audio amplifier," in Audio Engineering Society Convention 137. Audio Engineering Society, 2014.

[14] K. Jha, S. Mishra, and A. Joshi, "High-quality sine wave generation using a differential boost inverter at higher operating frequency," IEEE Transactions on Industry Applications, vol. 51, no. 1, pp. 373-384, 2015.

[15] N. Iversen, T. Birch, and A. Knott, "Utilization of non-linear converters for audio amplification," in Audio Engineering Society Conference: 48th International Conference: Automotive Audio. Audio Engineering Society, 2012.

[16] S. Chaput, D. Brooks, and G. Y. Wei, "A 3-to-5v input 100vpp output $57.7 \mathrm{mw} 0.42 \%$ thd $+\mathrm{n}$ highly integrated piezoelectric actuator driver," in 2017 IEEE International Solid-State Circuits Conference (ISSCC), Feb 2017, pp. 360-361.

[17] F. Su, W. H. Ki, and C. Y. Tsui, "Ultra fast fixed-frequency hysteretic buck converter with maximum charging current control and adaptive delay compensation for dvs applications," IEEE Journal of Solid-State Circuits, vol. 43, no. 4, pp. 815-822, April 2008.

[18] N. Keskar and G. A. Rincon-Mora, "Self-stabilizing, integrated, hysteretic boost dc-dc converter," in 30th Annual Conference of IEEE Industrial Electronics Society, 2004. IECON 2004, vol. 1, Nov 2004, pp. 586-591 Vol. 1.

[19] B. Bryant and M. K. Kazimierczuk, "Modeling the closed-current loop of pwm boost dc-dc converters operating in $\mathrm{ccm}$ with peak current-mode control," IEEE Transactions on Circuits and Systems I: Regular Papers, vol. 52, no. 11, pp. 2404-2412, 2005.

[20] T. Sai and Y. Sugimoto, "A method for realizing a fast response time for the output current change of a mos current-mode buck dcdc converter which utilizes a quadratic and vin-dependent compensation slope," in Solid-State Circuits Conference, 2009. A-SSCC 2009. IEEE Asian. IEEE, 2009, pp. 337-340.

[21] T. Grote, F. Schafmeister, H. Figge, N. Frohleke, P. Ide, and J. Bocker, 
"Adaptive digital slope compensation for peak current mode control," in Energy Conversion Congress and Exposition, 2009. ECCE 2009. IEEE. IEEE, 2009, pp. 3523-3529.

[22] S. Zhou and G. A. Rincon-Mora, "A high efficiency, soft switching dc-dc converter with adaptive current-ripple control for portable applications," IEEE Transactions on circuits and systems part 2 express briefs, vol. 53, no. 4, p. 319, 2006.

[23] H. Ma, R. van der Zee, and B. Nauta, "A high-voltage class-d power amplifier with switching frequency regulation for improved high-efficiency output power range," Solid-State Circuits, IEEE Journal of, vol. 50, no. 6, pp. 1451-1462, 2015.

[24] S.-W. Hong, S.-H. Park, T.-H. Kong, and G.-H. Cho, "Inverting buckboost dc-dc converter for mobile amoled display using real-time selftuned minimum power-loss tracking (mplt) scheme with lossless softswitching for discontinuous conduction mode," IEEE Journal of SolidState Circuits, vol. 50, no. 10, pp. 2380-2393, 2015.

[25] T. Szepesi, "Stabilizing the frequency of hysteretic current-mode dc/dc converters," IEEE Transactions on Power Electronics, vol. PE-2, no. 4, pp. 302-312, Oct 1987.

[26] A. Hasan, S. Gregori, I. Ahmed, and R. Chik, "Monolithic dc-dc boost converter with current-mode hysteretic control," in 2011 24th Canadian Conference on Electrical and Computer Engineering(CCECE), May 2011, pp. $001242-001245$.

[27] Y. Wen and O. Trescases, "Analysis and comparison of frequency stabilization loops in self-oscillating current mode dc-dc converters," IEEE Transactions on Power Electronics, vol. 28, no. 10, pp. 47534766, 2013.

[28] P. Midya, M. Greuel, and P. T. Krein, "Sensorless current mode controlan observer-based technique for dc-dc converters," in Power Electronics Specialists Conference, 1997. PESC'97 Record., 28th Annual IEEE, vol. 1. IEEE, 1997, pp. 197-202.

[29] C. F. Lee and P. K. Mok, "A monolithic current-mode cmos dc-dc converter with on-chip current-sensing technique," IEEE journal of solid-state circuits, vol. 39, no. 1, pp. 3-14, 2004.

[30] C. Y. Leung, P. K. Mok, K. N. Leung, and M. Chan, "An integrated cmos current-sensing circuit for low-voltage current-mode buck regulator," IEEE Transactions on Circuits and Systems II: Express Briefs, vol. 52, no. 7, pp. 394-397, 2005.

[31] H. P. Forghani-Zadeh and G. A. Rincón-Mora, "An accurate, continuous, and lossless self-learning cmos current-sensing scheme for inductorbased dc-dc converters," IEEE Journal of Solid-State Circuits, vol. 42 , no. 3, pp. 665-679, 2007.

[32] T. I. DRV8662, "Piezo haptic driver with integrated boost converter," Tech. Rep., Dec. 2014.

[33] C. Wallenhauer, B. Gottlieb, R. Zeichfusl, and A. Kappel, "Efficiencyimproved high-voltage analog power amplifier for driving piezoelectric actuators," IEEE Transactions on Circuits and Systems I: Regular Papers, vol. 57, no. 1, pp. 291-298, Jan 2010.

[34] M. Berkhout, L. Breems, and E. van Tuijl, "Audio at low and high power," in Solid-State Circuits Conference, 2008. ESSCIRC 2008. 34th European. IEEE, 2008, pp. 40-49.

[35] I. D. Mosely, P. H. Mellor, and C. M. Bingham, "Effect of dead time on harmonic distortion in class-d audio power amplifiers," Electronics Letters, vol. 35, no. 12, pp. 950-952, Jun 1999.

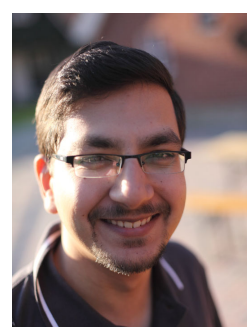

Saifullah Amir received BE degree in electronics engineering from National University of Sciences and Technology (NUST), Pakistan in 2006. In 2009 he received the MSc degree in electrical engineering from Royal Institute of Technology (KTH), Stockholm, Sweden. From 2009 to 2011 he worked as Lecturer at NUST, Pakistan. From 2011 he is working towards the PhD degree on the subject of energy efficient acoustic driver design for underwater wireless sensor networks at the University of Twente, The Netherlands. His research interests include DCDC converters, audio amplifies and mixed signal circuits.

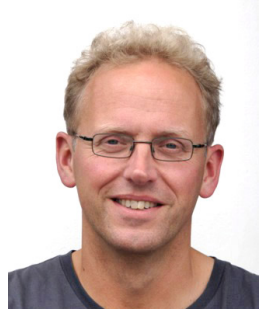

Ronan van der Zee (M07) received the M.Sc. (cum laude) degree in electrical engineering and the Ph.D. degree in high efficiency audio amplifiers from the University of Twente, Enschede,The Netherlands, in 1994 and 1999, respectively. In 1999 he joined Philips Semiconductors, where he worked on class AB and class D audio amplifiers. In 2003, he joined the IC-Design Group, University of Twente. His research interests include linear and switching power amplifiers, RF frontends and ultralow power radio.

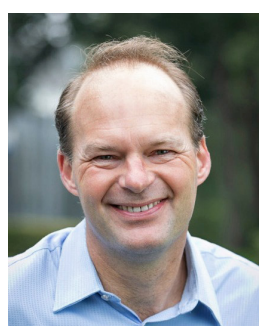

Bram Nauta was born in 1964 in Hengelo, The Netherlands. In 1987 he received the M.Sc degree (cum laude) in electrical engineering from the University of Twente, Enschede, The Netherlands. In 1991 he received the Ph.D. degree from the same university on the subject of analog CMOS filters for very high frequencies. In 1991 he joined the MixedSignal Circuits and Systems Department of Philips Research, Eindhoven the Netherlands. In 1998 he returned to the University of Twente, where he is currently a distinguished professor, heading the IC Design group. Since 2016 he also serves as chair of the EE department at this university. His current research interest is high-speed analog CMOS circuits, software defined radio, cognitive radio and beamforming.

He served as the Editor-in-Chief (2007-2010) of the IEEE Journal of SolidState Circuits (JSSC), and was the 2013 program chair of the International Solid State Circuits Conference (ISSCC). He is currently the President of the IEEE Solid-State Circuits Society (2018-2019 term).

Also, he served as Associate Editor of IEEE Transactions on Circuits and Systems II (1997-1999), and of JSSC (2001-2006). He was in the Technical Program Committee of the Symposium on VLSI circuits (2009-2013) and is in the steering committee and programme committee of the European Solid State Circuit Conference (ESSCIRC). He served as distinguished lecturer of the IEEE, is co-recipient of the ISSCC 2002 and 2009 "Van Vessem Outstanding Paper Award" and in 2014 he received the Simon Stevin Meester award (500.000), the largest Dutch national prize for achievements in technical sciences. He is fellow of the IEEE and member of the Royal Netherlands Academy of Arts and Sciences (KNAW) 